\title{
Contributions on experimental research of fuel consumption and management system in K9K892 Diesel engine from Dacia- Renault
}

\author{
Doru Baldean ${ }^{1, *}$, and Adela-Ioana Borzan ${ }^{1}$ \\ ${ }^{1}$ Tehnical University of Cluj-Napoca, Automotive and Transportation Department, 400641 Muncii Boulevard, Romania
}

\begin{abstract}
The present paper develops an experimental study that highlights some aspects of fuel consumption in engine's cylinders in order to outline the influence of engine's management system and operating conditions upon economy and fuel consumption, with corresponding effect on sustainability and adequate socio-economic development. The present work makes a theoretical and applied enquiry in the system features from Euro 5 diesel engine management in relation with fuel consumption and different driving scenarios. There were closely monitored engine temperatures, driving stiles and the values displayed ONBOARD-DIAGNOSIS screens. The importance and opportunity for experimental inquiry of the fuel consumption and economy problems in compression ignited engine resides in the state of the art equipment and managing systems available today for monitoring all the engine's activities and for making possible to outline the economical operating regime, in order to reduce undesired losses. The experimental data are analyzed in detail.
\end{abstract}

\section{Introduction}

This study is continuing a theoretical and experimental research program which is a part of the internal research enquiry started a while ago at Technical University from Cluj-Napoca, being for the present moment a particular phase of a particular project.

Nowadays, pollutant gas reduction and fuel economy is less an alternative or secondary priority but more like one of the important aspects to be considered with all rigorousness. We have to prioritize a lot in this direction. Besides dreaming to eco-friendly engines, which will consume and pollute less (even if this is possible at all), there have to be taken into consideration meanwhile also the operating engines, and the eco-performance level, which were not designed taking into account all the aspects mentioned by strictest criteria in the field [1].

Today, the expectations concerning management and fuel supply systems for internal combustion engines are at high level and delicately considered. The engine's operation cycle is electronically controlled by a complex management system which reduces fuel and thermal loses. Thus it is important and quite necessary to reorganize and redefine the classical knowledge and analyzing methods for engine's operation in order to improve eco-performances and reduce pollution [2-6].

The research work outlines a set of engine operating features from the electronic management system, and a specific study of the fuel supply system from Dacia Logan Euro 5 diesel engine, and also a data package from the experimental measurements concerning the eco-level in various operating conditions during the field tests developed on a real motor vehicle.

\section{State of the art}

\subsection{Study of the scientific literature}

For a diesel engine, fuel injection pressure (FIP) and injection timings are very important parameters, which influence the engine performance, emissions, and combustion. Other operational and injection parameters affecting engine performance are rate of injection, injection pattern, number of injections [1], coolant temperature, working stability level etc. [2], [3], [4], [5].

Great concerns are growing up on the environmental impact of fossil fuel and poor air quality in urban area due to traffic-related air pollution. In recent years particular attention was paid mainly to the toxic emissions (HChydrocarbons, CO-carbon oxide, PM-particulate matter and NOx-nitrous oxides) of diesel engines for their negative effects on human health and photochemical smog. Nowadays, the overall concern about the global warming problem has changed the social interest of the pollutant emissions so that an increasing attention is building up also for $\mathrm{CO} 2$ emissions, one of the major greenhouse gases. A significant improvement can be obtained with the increase of the use of "clean" and renewable fuels. Some of them may offer the possibility to overcome the emission regulations without significant changes to engine layout and fuel economy. As it is known, great attention is given to the fatty-acid methyl-

* Corresponding author: doru.baldean@auto.utcluj.ro 
esters (generally named with its acronym FAME or more generally as "biodiesel") [2].

The Dieselgate scandal has already raised questions in Europe about the accuracy of emissions testing, putting other automakers on the defensive position. Environmental groups have long complained that existing tests understate the amount of pollution that cars generate under real driving conditions [6].

\subsection{Our related research of the problem}

Our research staff promotes a constant evolution for knowledge and scientific programs for optimizing automotive engines and for a healthy environment and less polluted society.

Reductions in brake specific fuel consumption and pollutant emissions are correlated with the use of bio-fuel and ultrasonic technology, comparative to use of known fuel blends. Considering the fuel consumption as Diesel engine's main performance parameter, the proposed fuel supply method, offers the possibility to use more efficient renewable biofuels (bioethanol), with immediate effects on environmental protection [5].

A similar research, as an overview of the problem, showed that the fuel supply system influence on the engine economy may be affected by injection characteristics and also by each auxiliary system proper performance which may be monitored with the state of the art technologies which are available today [3].

\section{Mathematical apparatus}

Outlining all the important parameters related to the fuel consumption, vehicle speed, engine power, and pollutant generation is significant in order to understand the mathematics which stands behind the results.

Fuel consumption is determined with the mathematical relation [7]:

$$
\mathrm{C}_{\mathrm{h}}=3.6 \frac{\mathrm{I}_{\mathrm{V}} \cdot \rho}{\mathrm{t}}=3.6 \frac{\mathrm{I}_{\mathrm{m}}}{\mathrm{t}}
$$

in which: $\mathrm{I}_{\mathrm{V}}$ is the fuel injected volume, in $[\mathrm{ml}] ; \mathrm{t}-$ measuring time interval, in $[\mathrm{s}] ; \rho-$ fuel density, in $[\mathrm{kg} / \mathrm{h}]$; $\mathrm{I}_{\mathrm{m}}$ - the fuel mass in [mg].

Effective power output is calculated with the mathematical expression [8]:

$$
P_{e}=\frac{p_{e} \cdot n \cdot i \cdot V_{s}}{30000 \cdot \tau},
$$

in which: pe is the brake mean effective pressure; $n-$ engine speed; $\mathrm{i}$ - number of cylinders; Vs - cylinder-unit volume; $\tau$ - number of engine strokes.

Effective fuel specific consumption is calculated with the relation [7]:

$$
\mathrm{c}_{\mathrm{e}}=\frac{\mathrm{C}_{\mathrm{h}}}{\mathrm{P}_{\mathrm{e}}}=3.6 \frac{\mathrm{I}_{\mathrm{m}}}{\mathrm{P}_{\mathrm{e}} \cdot \mathrm{t}},
$$

in which: Ch is the hourly fuel consumption $[\mathrm{kg} / \mathrm{h}] ; \mathrm{Pe}-$ effective power output $[\mathrm{kW}]$.

\section{Methodology}

Methodology for testing the eco-performance and fuel consumption parameters follows a protocol similar to the one presented in figure 1.

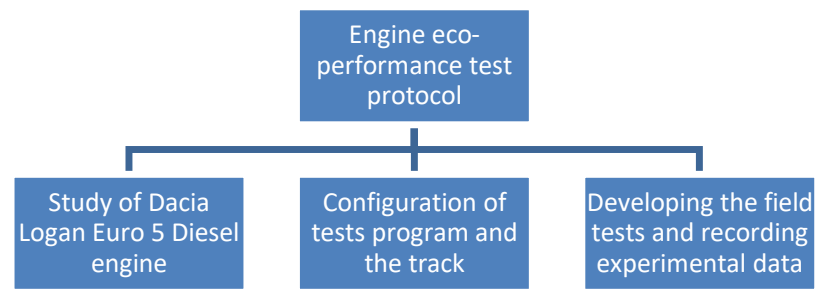

Fig. 1. Main protocol applied in the field tests

Testing method relies on the connection of digital devices to the engine's management system in order to collect and store the experimental data. Useful apparatus for the development of experimental tests were the Bosch KTS OFF-BOARD-DIAGNOSIS system with a user-friendly graphic interface and a motor vehicle (Dacia Logan with K9K892 Euro 5 engine).

The link through the CAN-BUS electronic communication interface has the objective of allowing a research staff member to configure the engine-scanning protocol and to define all parameters in which the management system of the engine works and acquire the available experimental data during operating time in field tests (Figure 2).

For enquiring the field measurements are used ESItronic applications and KTS Bosch 650 equipment. At their operating electronic base these programs have complex mathematical models. Main apps are using the analog values measured by the sensors, converted then to digital code. With the technology progress experimental protocols became very complex and the restrictions which were in the former systems are now diminished.

This work presents an innovative procedure for field testing of the engine management system in real operating scenarios by using state of the art equipment and latest communication strategies in order to monitor and record the engine eco-behavior with the electronic control unit (ECU).

This innovative method of computer assisted testing (CAT) allows the researcher to evaluate the phenomenology of actual values variation in real operation conditions in order to correlate the important parameters with signs and symptoms. Thus car and especially the engine's semiotics may be improved and thoroughly defined.

It took some years in training to bring more packages of data in order to improve this new method of study by testing and to implement it while the vehicle is in motion and all the parameters are oscillating due to different working conditions.

Cumulating operational data from engine in various regimes and scenarios it improves the whole "picture" of 
entire phenomenology, which will be never exhaustive and absolutely completed, just better defined.

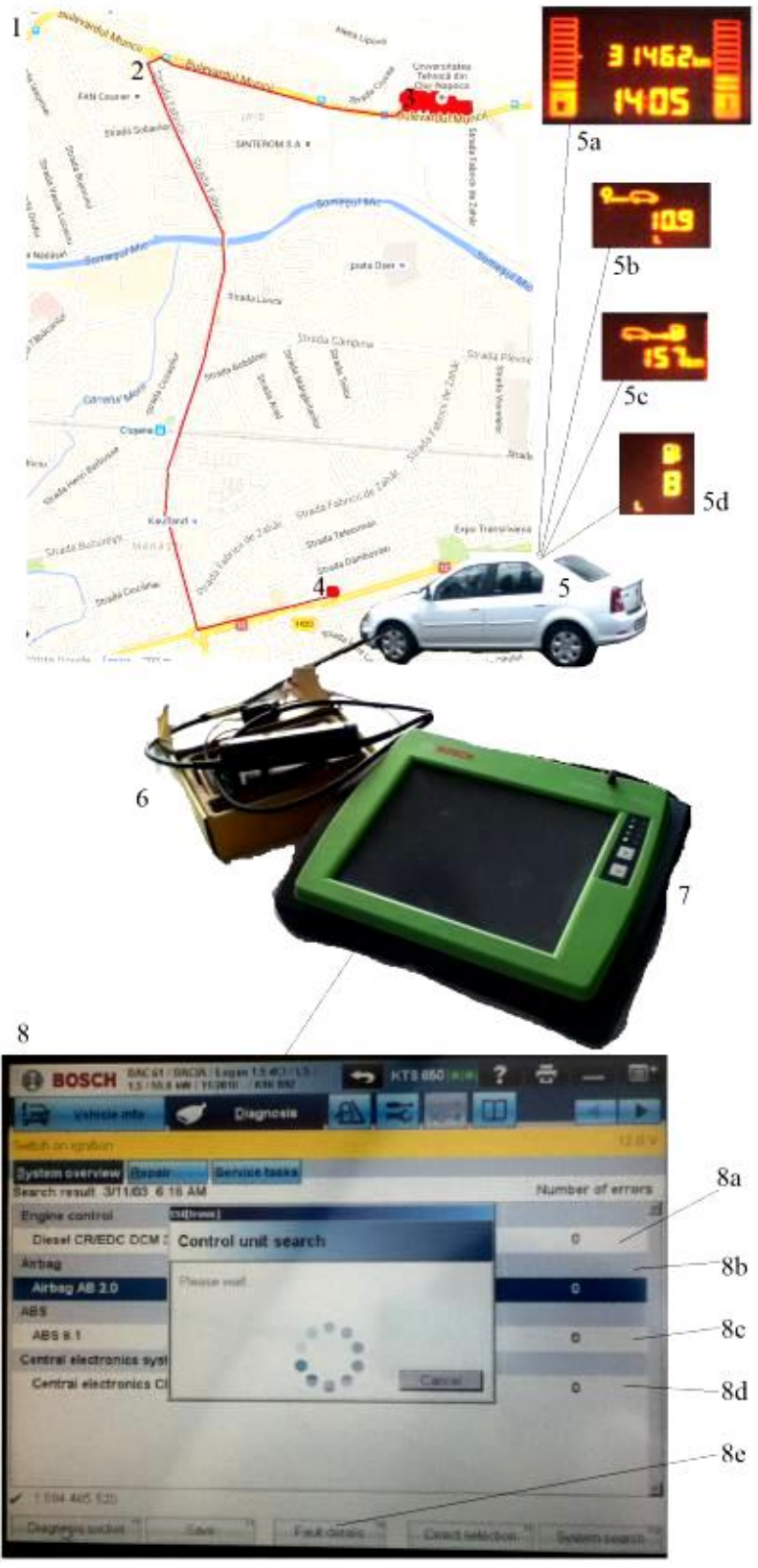

Fig. 2. Experimental set for ECU-KTS communication 1-experiment site map; 2-track, 3-start-point; 4-end-point; 5tested vehicle; 5a-ON-BOARD display with total number of $\mathrm{km}$; 5b-consumed fuel quantity during tests; $5 \mathrm{c}$-mileage; $5 \mathrm{~d}$ fuel quantity in the vehicle's tank; 6-analog-digital converter; 7-KTS-Bosch 650; 8-graphic interface; 8a-engine module link; 8b-airbag; 8c-Anti-lock Braking System; 8d-fault details.

\section{Analyze of the experimental data}

\subsection{Test protocol configuration}

Recording the measurements and tracking the engine ecoperformance during the field tests were realized with a specialized electronic data management system, which consists of portable devices and also data storage units for post-processing. Euro 5 compression ignited engine is installed on a Dacia Logan vehicle linked with a electronic management and scanning system. Also the fuel tank is monitored with the ON-BOARD available default program.

Figure 3 shows the ECU available systems on the tested vehicle at the time of test protocol configuration.

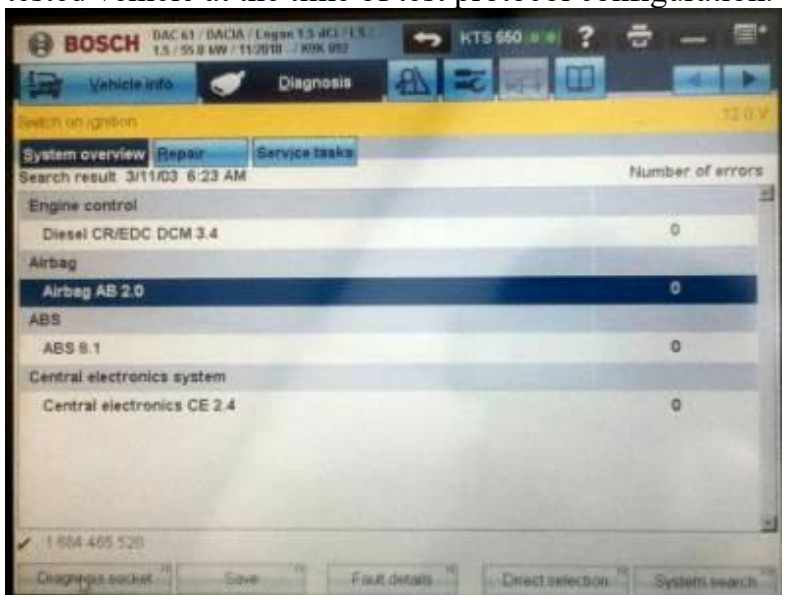

Fig. 3. ECU available systems

\subsection{Electronic Diesel Common-Rail control module}

In order to acquire reliable engine operational data the electronic diesel control (EDC) module is activated (Figure 4) which allows us to identify the management system.

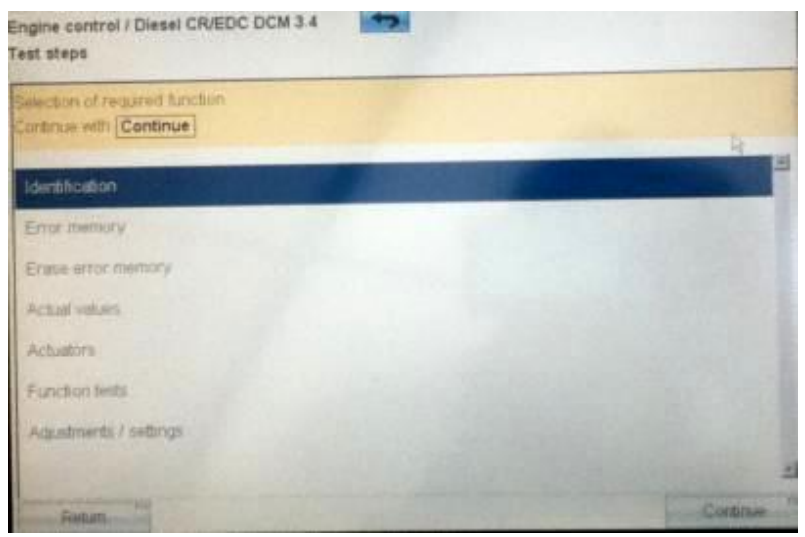

Fig. 4. Engine control module for identification

After the engine identification procedure (Figure 4) we proceed to actuators scanning (Figure 5) and actual values monitoring (Figure 6).

\section{Actual values}

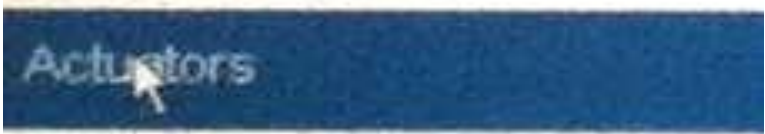

\section{Function tests}

\section{Avdjustments / seltings}

Fig. 5. Digital scanning of the engine's actuators 


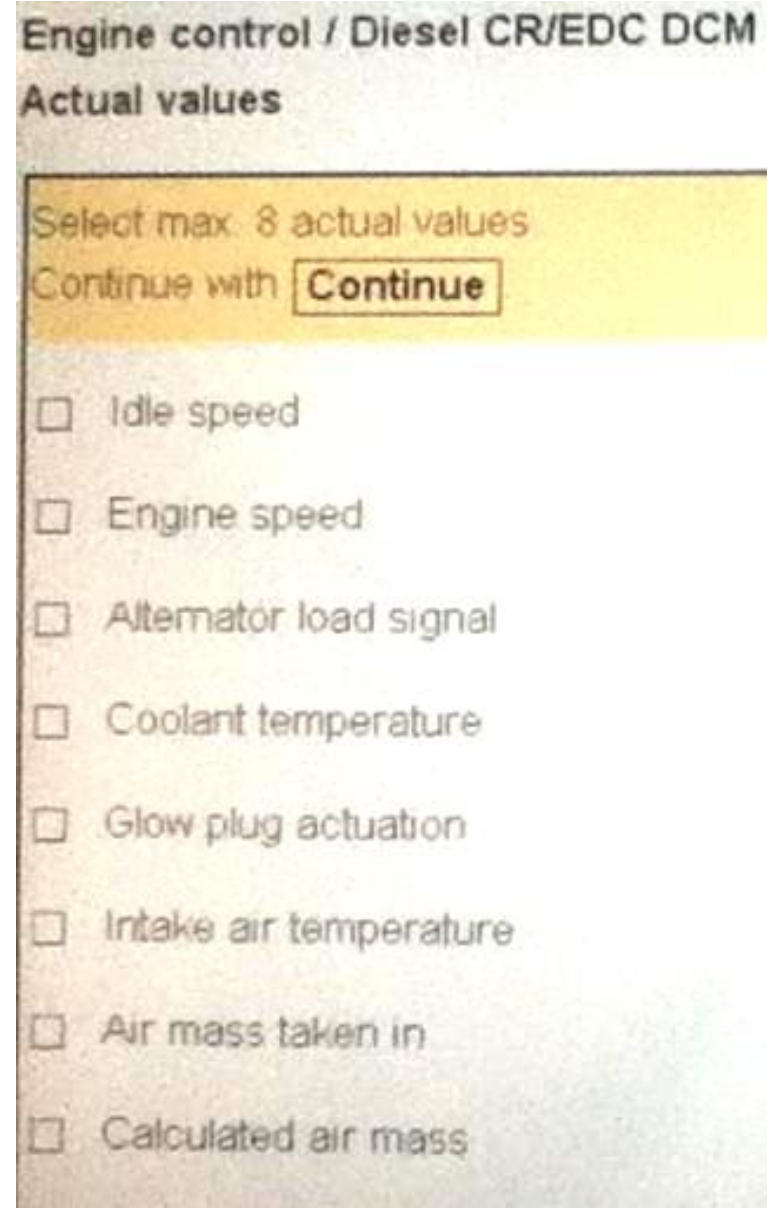

Fig. 6. Selecting the monitored and recorded actual values

Fuel consumption was monitored ON-BOARD in different operation conditions (Table 1).

Table 1. Values for fuel consumption in urban driving conditions

\begin{tabular}{|c|c|c|}
\hline Symbol & Quantity & Experimental values \\
\hline $\mathrm{C}_{1}$ & $\begin{array}{c}\text { Fuel consumption (FC) } \\
\text { when defensive driving } \\
\text { strategy is applied }\end{array}$ & $\begin{array}{c}\text { FC in defensive driving, } \\
\text { but engine is under } 60^{\circ} \mathrm{C} \\
\text { coolant temperature }\end{array}$ \\
\hline $\mathrm{C}_{2}$ & $\begin{array}{c}\text { Rush hour defensive } \\
\text { driving, engine is } \\
60 \div 80^{\circ} \mathrm{C} \text { coolant } \\
\text { temperature }\end{array}$ \\
\hline $\mathrm{C}_{3}$ & $\begin{array}{c}\text { Air-conditioning on, } \\
\text { engine is } 60 \div 80^{\circ} \mathrm{C} \\
\text { coolant temperature }\end{array}$ \\
\hline $\mathrm{C}_{4}$ & $\begin{array}{c}\text { Not defensive driving, } \\
\text { engine is } 60 \div 80^{\circ} \mathrm{C} \\
\text { coolant temperature } \\
\text { (headlights on, }\end{array}$ \\
\hline $\mathrm{C}_{6}$ & $\begin{array}{c}\text { Beginner style driving, } \\
\text { engine is } 60 \div 80^{\circ} \mathrm{C} \\
\text { coolant temperature } \\
\text { (headlights on, }\end{array}$ \\
\hline
\end{tabular}

\subsection{Actual values and accelerator sensors}

The readings from electronic control module corresponding to the actual values were accessed progressively (Fig. 5-9). Also the battery voltage, power supply for sensors and glow control were closely monitored.

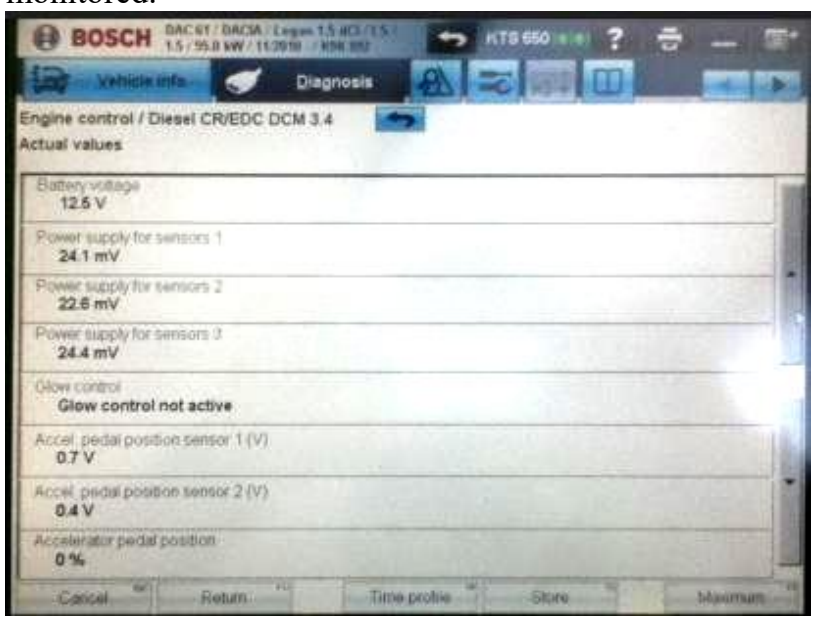

Fig. 7. Actual values for power voltage and accelerator pedal

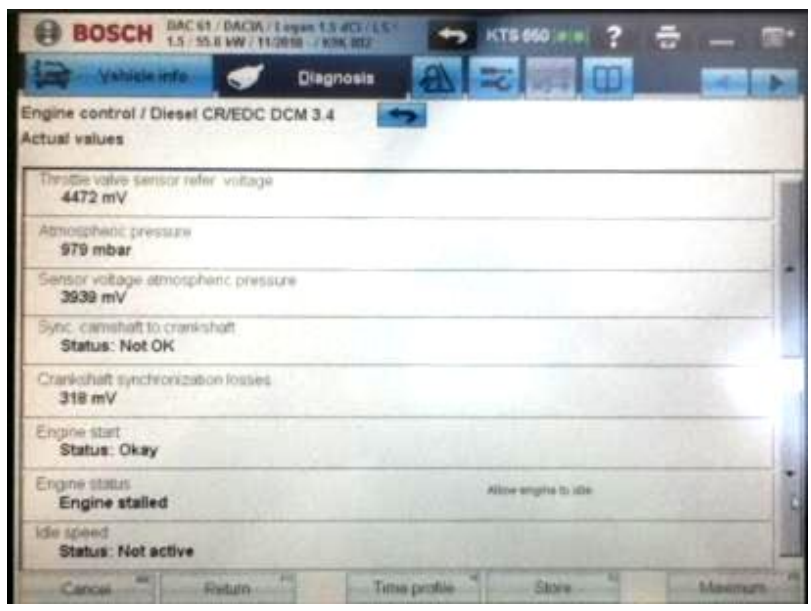

Fig. 8. Actual values for throttle valve and crankshaft sensors

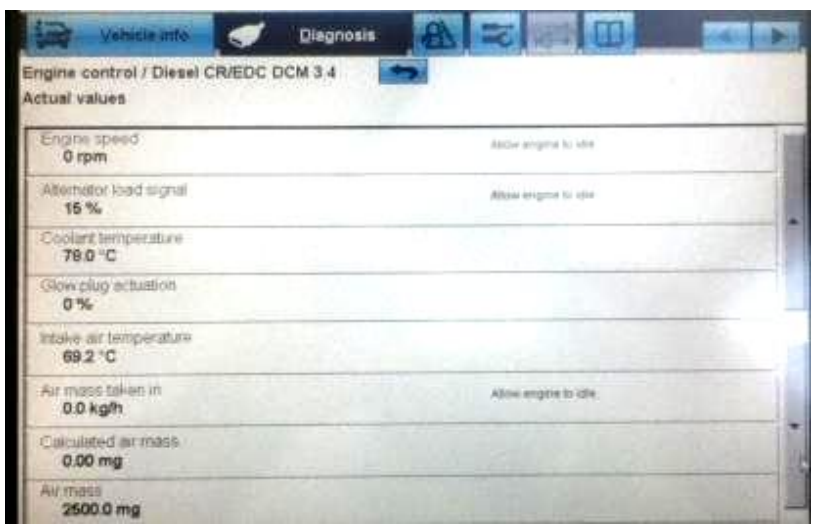

Fig. 9. Engine speed and air mass when engine stalled/stopped It was observed that the fuel consumption and the fuel injected quantity in all cases of driving and operation conditions are close related to the engine's temperature and load. Also, the accelerator pedal position is essential for fuel injection management. 


\subsection{Fuel injection and exhaust gas recirculation}

Fuel nominal pressure in the common rail system is at idle engine speeds 271 bar (Figure 10).

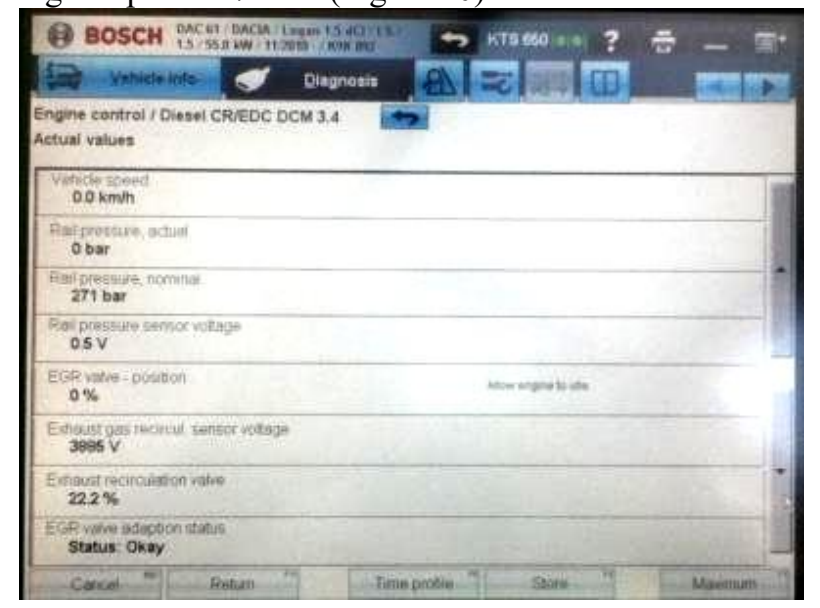

Fig. 10. Injection system and exhaust gas recirculation

Exhaust gas recirculation (EGR) deviation and cooler regeneration, besides fuel temperature and injected quantity are scanned with the ECU and KTS (Figure 11).

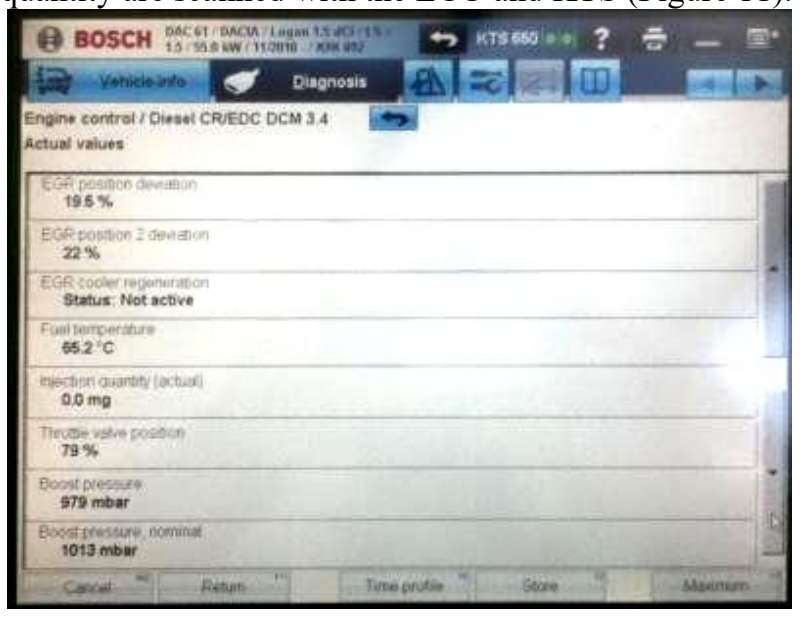

Fig. 11. Injection, EGR and air boost systems

Boost pressure sensor voltage for the supercharge system and particulate filter soot impact are monitored like shown in the (Figure 12).

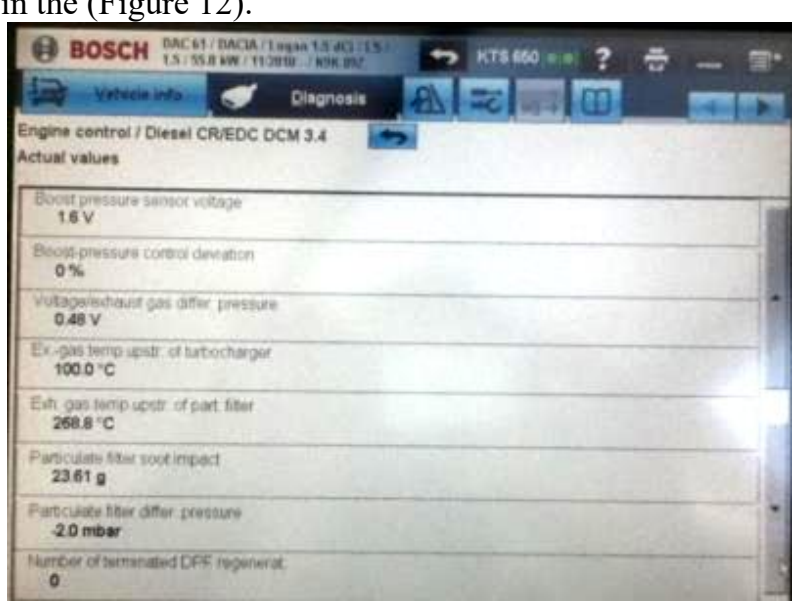

Fig. 12. Supercharger and particulate filter status
Diesel particulate filter (DPF) details like time since last regeneration and its duration, traction control and the possibility of air conditioning activation are also monitored (Figure 13).

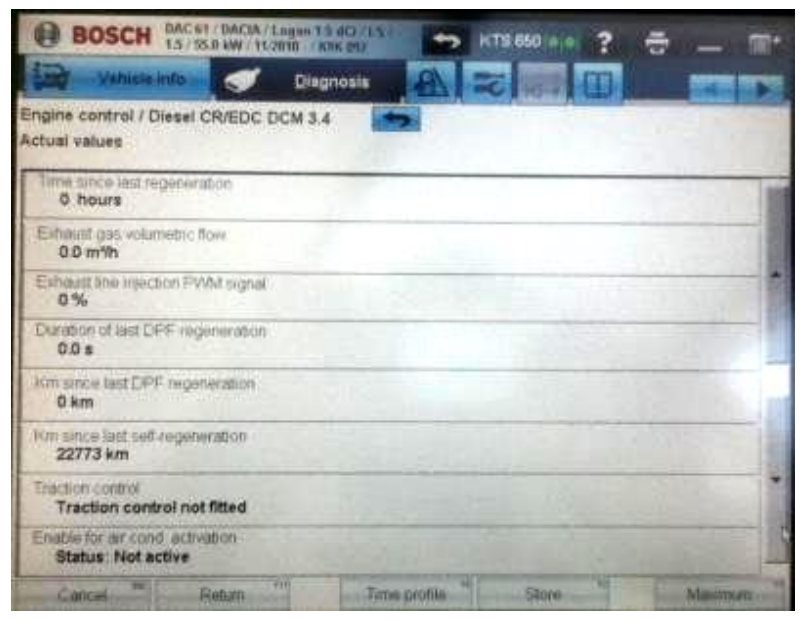

Fig. 13. Diesel particulate filter regeneration details

Cruise control if existing, vehicle speed, exhaust line and gear features were also monitored (Figure 14).

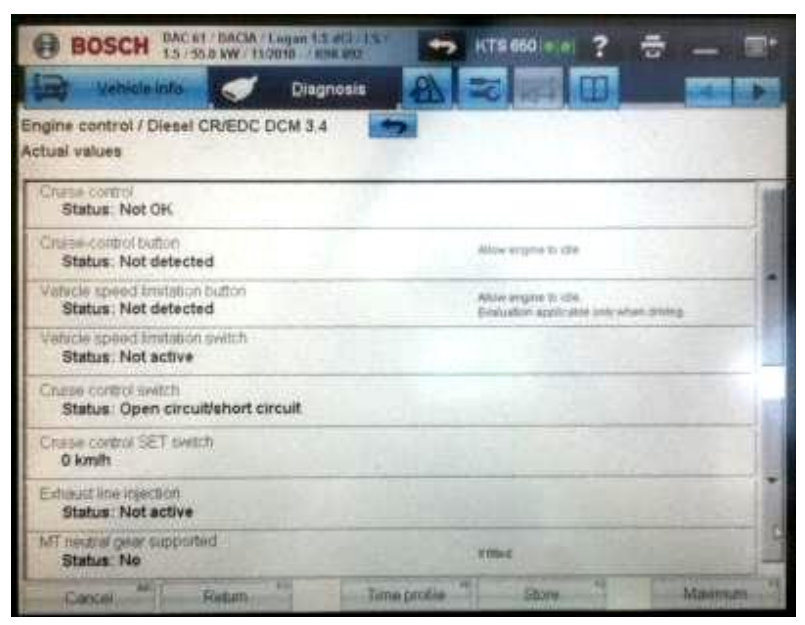

Fig. 14. Dynamic control monitoring

Transmission, reverse gear, vehicle speed, and auxiliary features were recorded (Figure 15).

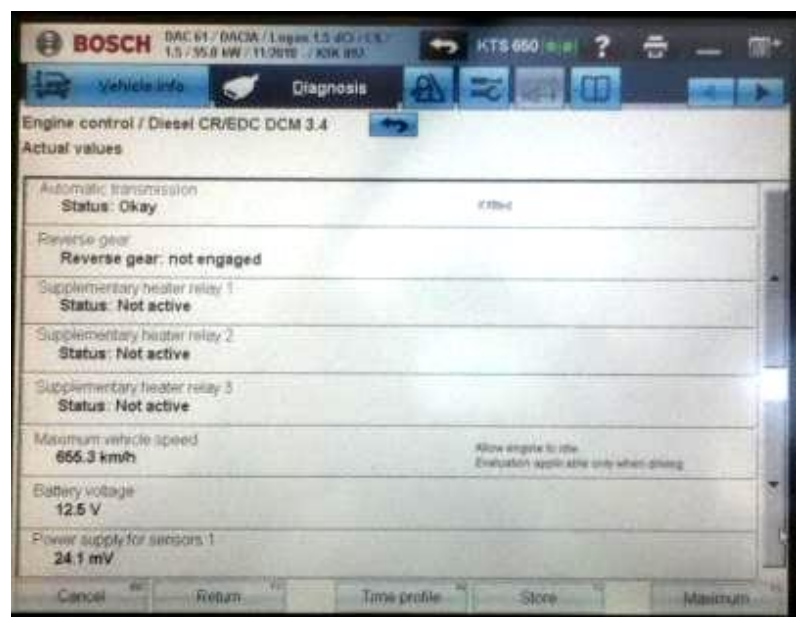

Fig. 15. Transmission and vehicle control monitoring 


\subsection{Common rail high-pressure test}

In the experimental testing process there was also monitored and followed the high pressure test for the common-rail (CR) fuel pump (Figure 16).

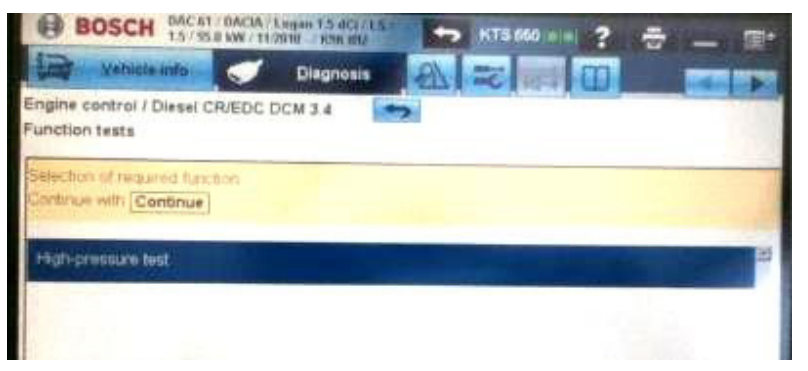

Fig. 16. Access of the high pressure test in CR system

Other adjustments and settings were made in injection quantity, crankshaft adaption, intake manifold, and exhaust systems (Figure 17).

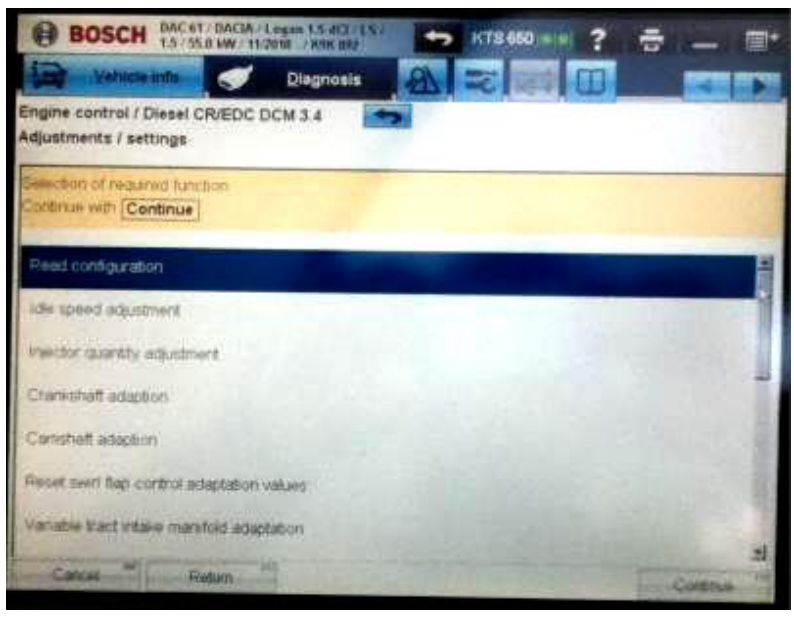

Fig. 17. Configurations, adjustments and settings in engine's electronic management system

ECU facilitate the EGR adaptation values, rail pressure sensor adjustment, fuel pump setting and to access other features in the management system (Figure 18).

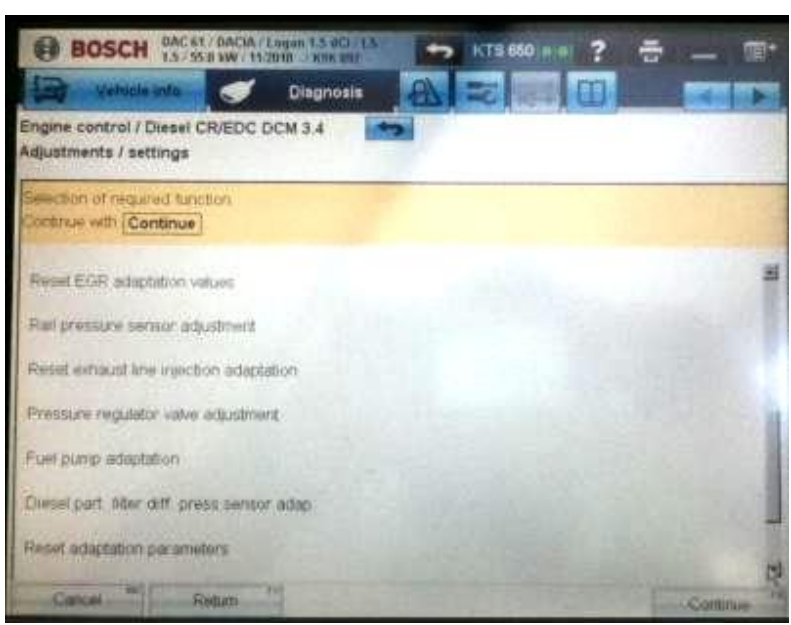

Fig. 18. Adjustments and settings in engine's electronic diesel management system
Vehicle identification number and diagnosis version are shown also (Figure 19).

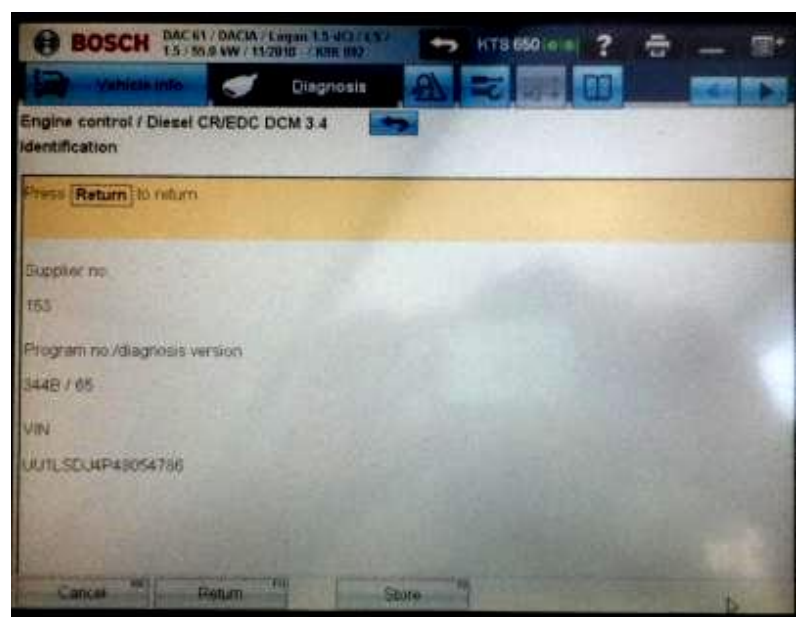

Fig. 19. Diagnosis version and vehicle identification

\section{Conclusion}

The paper presents an experimental enquiry in the field of fuel consumption and engine management system on real diesel engine during operation. Future papers will study alternative fumigation methods on classic systems.

\section{References}

1. A. K. Agarwala, D. K. Srivastavaa, A. Dhara, R. K. Mauryaa, P. C. Shuklab, A. P. Singha, "Effect of fuel injection timing and pressure on combustion, emissions and performance characteristics of a single cylinder diesel engine," Fuel, 111, pp. 374-383, 2013.

2. B. Carlo, C. Guido, S. Di Iorio, "Experimental analysis of alternative fuel impact on a new "torque-controlled" light-duty diesel engine for passenger cars," Fuel, 89(11), pp. 3278-3286, 2010.

3. D. Baldean, "Contributions to the research and testing of modern diesel engines for certification and homologation of performances and emissions." Vol. 45, Inginerie agrară şi transport auto, Chișinău, R. Moldova, pp. 146-150, 2015.

4. D. Baldean, "Studies and researches concerning modeling the combustion process in compression ignited engine in biodiesel use conditions for improving engine's performances" (Studii şi cercetări privind modelarea procesului de ardere în motorul cu aprindere prin comprimare în condiţiile utilizării biodieselului pentru îmbunătăţirea performanțelor motorului) Doctoral thesis, UTPress, 2011.

5. F. Mariasiu, N.V. Burnete, D. Moldovanu, B.O. Varga, C Iclodean, L. Kocsis, "Effects of bioethanol ultrasonic generated aerosols application on diesel engine performances." Thermal Science, Vol. 19, No. 6, pp. 1931-1941, 2015

6. J. Ewing, "Volkswagen C.E.O. Martin Winterkorn Resigns Amid Emissions Scandal." New York Times, International Business, SEPT. 23, 2015.

7. N. Bataga, "Motoare termice. Lucrari practice" I.P.C-N., pp. 5760, 1988

8. N. Bataga, N. et al: "Internal combustion engines" (Motoare cu ardere interna). E.D.P., pp. 15-17, 1995.

9. L.-V. Crisan-Lupa, et al: Research applied to exhaust gas aftertreatment systems in 1.61 ZSG 416 Ford engine. in Proceedings of the European Automotive Congress EAEC-ESFA 2015, ISBN 978-3-319-27276-4, DOI 10.1007/978-3-319-27276-4, retrieved 22.03.2018 